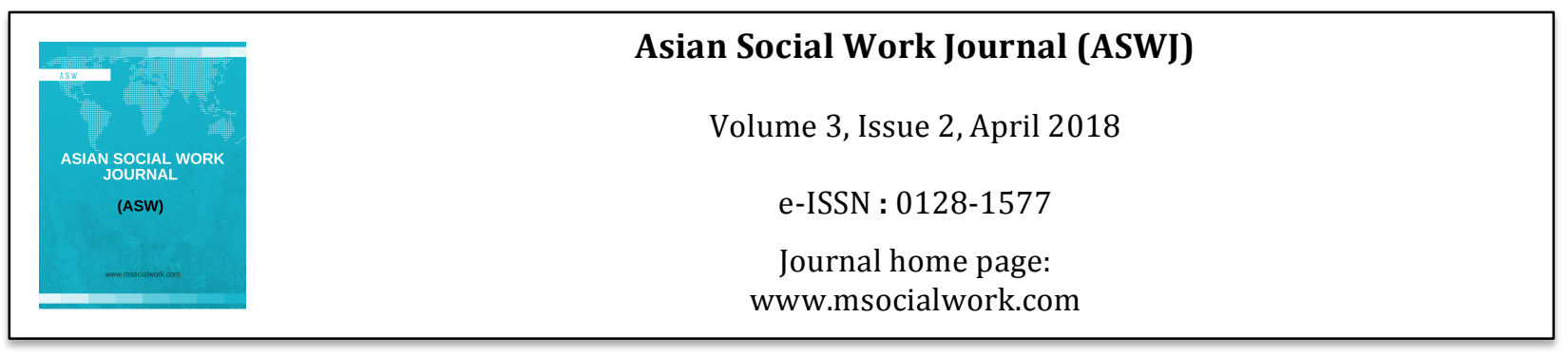

\title{
Child Maltreatment in Hanoi, Vietnam and Its Consequences
}

\author{
Nguyen Trung Hai ${ }^{1}$ \\ 1University of Labor and Social Affairs, Vietnam \\ Corrrespondence: Nguyen Trung Hai (hainguyentrung1979@gmail.com)
}

\begin{abstract}
Annually, number of child maltreatment has been increasing gradually. The consequences of child maltreatment and abuse seriously and directly impact child development both in physical and mental aspects and last in following years. Recently, researchers have paid more attention to studying child maltreatment in combination with community and neighborhood as a strong intervention to this issue. This paper aims to provide general information about child maltreatment in Hanoi and its consequences. Study shows that children in Hanoi Vietnam get involve in 4 types of maltreatment which are Minor abuse, Severe abuse, Very Severe abuse, Neglect. Being maltreated, it also causes many problems to child development. Thus, this study recomends some solutions to deal with those problems
\end{abstract}

Key words: child maltreatment, child development, intervention

\section{Introduction}

Our future definitely depends on children regardless of wherever you are, and whether your country is developed or not, or rich or poor. Aware of this, countries in the world have paid much to children in order to provide the best things for children's development. However, a lot of children are in fact suffering from maltreatment and abuse. According to a UNICEF report, approximately 500 million to 1.5 billion children have to suffer from violence annually. Each year, there are about 275 million children in the world suffering from child maltreatment and abuse in the family (UNICEF, 2009).

Children who are seriously abused and neglected may suffer from brain damage, resulting in impaired development for them (De \& Thomas, 2003). Specifically, the impaired development causes poor cognitive skills, difficulties in communication and poor learning capacity in school (Watts-English et al., 2006). Other studies show that child abuse and maltreatment cause psychological consequences (Dubowitz, Papas, \& Starr, 2002). According to Dubowitz, Papas, Black, \& Starr (2002) children who were mentally, physically abused and neglected tend to be depressive or withdraw from activities with other children. In addition, many child mental health problems such as vulnerability to panic, suffering from depression and getting furious or nervous are directly related to child mental, physical abuse and neglect (Teicher, 2000; De \& Thomas, 2003; Springer, Sheridan, Kuo, \& Carnes, 2007). Suffering abuse seems also to later result in some problems with behavior. Findings of the National Institute of Justice in 2004 indicated that the majority of juvenile children who were caught due to illegal activities experienced abuse and neglect (English, Widom, \& Brandford, 2004). Furthermore, children who were abused were likely to take substances such as tobacco and have addiction to alcohol or drugs (Dube et al., 2001). 
The tradition in Vietnam always take care of their children. However, there are many risk factors could cause child maltreatment behavior and whether it makes children get in any problem? Thus, it is very interesting to examine that issue. Using questionnaire from Families and Neighborhoods Study (Emery, 2010), this study thus examines 'Child maltreatment in Hanoi, Vietnam and its consequences' focusing on physical abuse and neglect.

\section{Method of study}

\section{Design of study}

Stage 1: Preparation: Looking for the information needed for the questionnaire from books, articles and papers.

Stage 2: Pilot study is conducted. This step will be discussed more detail in next part.

Stage 3: By conducting the main survey, hypotheses will be tested.

\section{Study participants}

Base on the results from a pilot study we calculated that 300 participants will be needed for $80 \%$ power in the main study. The sample frame is residents who live in Hanoi, Vietnam and have children. Respondents are people who live with their children, aged from 0 to below 18 years old. According to the Beijing Families and Neighborhoods Study about domestic violence (Emery, 2010), the optimum appears to be 20 or 25 clusters with $\mathrm{N}=200$ or 175 . Thus, with the total population of 300 , we will take 30 wards from Hanoi. Simple random samples of respondents will be drawn from lists of residents provided by the ward offices (10 respondents from each ward). This will provide a representative and 3 stage cluster sample.

\section{Measurement}

\section{Neighborhood scales (Neighborhood process and Neighborhood structure)}

Neighborhood process is normally measured by combining measures of neighborhood cohesion and measures of informal social control (Browning, 2002).

The informal social control scale (Sampson et al., 1997) is constructed from respondent assessments about their neighborhood. They were asked whether their neighbors could be counted on to intervene in various ways if (a) "children were skipping school and hanging out on a street corner,"(b) "You were away and someone was trying to steal your bike" (c) "a child was showing disrespect to an adult," (d) "there was a fight in front of your house/apartment". Responses were given on a 4-point scale, strongly agree; agree; disagree; strongly disagree, with higher values representing higher levels of agreement. Reliability for this scale was good (Cronbach's alpha $=0.87$ ).

The social cohesion scale (Sampson et al., 1997) is constructed from 4 items measuring the respondent's level of agreement (on a 4-point scale the same as the informal social control scale) with the following statements:(a)"people around here are willing to help their neighbors," (b) "this is a close-knit neighborhood,"(c) "people in this neighborhood can be trusted," (d)" You can get much care from your neighborhood if you or your family has some important problem". Reliability for this scale was excellent (Cronbach's alpha $=0.93)$.

Neighborhood structure consists of poverty and instability (Coulton et al., 1995). Poverty is measured by people who income below poverty threshold.

Instability: People who stayed in their neighborhood less than 5 years 
If a household was neither below the poverty line nor unstable (less than 5 years residence) Reliability for neighborhood structure was good (Cronbach's alpha $=0.88)$.

\section{Child maltreatment scales}

In this study, the Conflict Tactics Scales Parent Child CTSPC is used to measure the child physical abuse. Items, not relevant to Vietnamese culture, were removed or modified. Specifically, the item using a gun on the child was removed. This scale is divided into 3 levels as Minor (corporal punishment), Severe (physical abuse) and Very Severe (severe physical abuse). Actions with different levels or applying to different parts of the body are also given to respondents to measure the severity of child physical abuse. They are listed as follows: spanked by bare hand; hit him/her on the bottom or other parts of body with some hard object; slapped; pinched; shook; threw or knocked him/her down; grabbed him/her around the neck and choked him/her or burned and scalded him/her on purpose. The item using gun was removed as discuss above. The respondents were asked how many times they did those actions in the last year. The time interval is drawn as once; twice; 3 to 5 times; $6-10$ time, 11 to 20 times, and more than 20 times. Three new items will be added to capture child neglect. It is designed to measure care for the child in several aspects such as safety, medical care, and food. The frequency is the same as the scale of child physical abuse. Reliability for this scale was good (Cronbach's alpha $=0.82$ ).

\section{Sample selection (3 stage cluster design)}

Stage 1: I got a list of all wards in Hanoi. (PPS Sampling for Stage 1)

Stage 2: A simple random sample of households was selected based on police office lists of ward residents.

Stage 3: Household respondent was selected by most recent birth year.

\section{Research finding}

As presented in paragraph above, child maltreatment in the world is prevalent. Definitely, from the literature review, the rate of child maltreatment still remains high or has even increased in several countries. However, factors causing and controlling child maltreatment are different in different cultures. Thus, it is important to examine the child maltreatment problem in Vietnam and compare it with other countries. The data below was collected in Hanoi, Vietnam using 3 stage cluster sampling.

Table 1: Distribution of child maltreatment types

\begin{tabular}{lc}
\hline Child maltreatment & Percent \\
\hline Minor Abuse & 63.5 \\
Severe Abuse & 22.5 \\
Very Severe Abuse & 10.9 \\
Neglect & 14.0 \\
\hline
\end{tabular}

As we can see from table 1, minor child minor abuse has the highest rate $(63.5 \%)$ among child maltreatment types. As defined above minor child abuse is defined as spanked by bare hand; hit $\mathrm{him} /$ her on the bottom or other parts of body with some hard objects. According to several Vietnam studies, those actions are acceptable (Nguyen, 2009).

In Vietnam, derived from feudalism, many people still believe that beating a child with a rod is just to give good education for children; then they will be good people in future. Just actions such as spanking with bares hand; hitting him/her on the bottom with some hard objects, are used to make children become better (Nguyen, 2009). Those ideas are similar to ideas from other countries. Research in the 
USA found that $84 \%$ agreed "that it is sometimes necessary to discipline a child with a good hard spanking." (Durrant JE, 2005). A study in the Republic of Korea found that $90 \%$ of parents thought corporal punishment 'necessary' (Kim D.,H, 2008). In a report from Yemen, almost $90 \%$ of children said that physical and humiliating punishment is the main method of discipline in the family, with the most common form being beating (Habasch R, 2005). It could be reason why the rate of child minor abuse is high.

Also using the Conflict Tactics Scales, another study, comparing rates of violence against children in China and the Republic of Korea showed that $70.6 \%$ (minor $42.2 \%$; serious $22.6 \%$ ) of the children in China and 68.9\% (minor 9.4\%; serious 51.3\%) of those in Korea (Kim D.,H, 2008) suffered from physical abuse. Thus, we can see in this study, Vietnamese minor physical abuse has the highest rate (63.5). Severe physical violence seems lower. It is almost the same rate of severe abuse in China $(22.5 \%)$ but lower than Korea. Very severe abuse such as grabbed him/her around the neck and choked him/her or burned and scalded him/her on purpose, are reported as having the lowest rate among physical abuse types. $10.9 \%$ of respondents said that they did that at least once in the past 6 months.

Child neglect, here, means the failure of parents or carers to meet a child's physical and emotional needs when they have the means, knowledge and access to services to do so; or failure to protect her or him from exposure to danger. However, in many settings the line between what is caused deliberately and what is caused by ignorance or lack of care possibilities may be difficult to draw. In Kenya, abandonment and neglect were the most commonly cited aspects of child abuse when adults in the community were questioned on the subject (Awareness and views, 2009). In that study, 21.9\% of children reported that they had been neglected by their parents. According to the report of Straus, M.A., Savage, S.A (2003), the prevalence of childhood neglect ranged from $10 \%$ in Montreal, Quebec, Canada, $19.4 \%$ in Singapore. In 2008, the U.S state and local child protective services received 3.3 million reports of children being abused or neglected. Seventy-one percent of the children were classified as victims of child neglect (UNICEF' report about Child Abuse \& Neglect, 2010).

Neglect in this study is grouped by failure to provide adequate food, safety and medical care. Here, around $14 \%$ reported that they have at least once not cared for their children in terms of medical care, food and safety. Researchs show that children need to have much care from parents to guarantee their healthy development. So lacking care from them it could be cause many problems which badly effect to them. So, we do need to scan specifically its consequences to children to recommend effective solutions. However, before going to see its consequences, we should test the relationship between child maltreatment behavior and respondents' characteristic.

Table 2: Full Logistic Regression Models:

Relationship between respondents' characteristic and child maltreatments' types

\begin{tabular}{|c|c|c|c|c|}
\hline & $\begin{array}{c}\text { Minor Abuse } \\
\text { OR (SE) }\end{array}$ & $\begin{array}{c}\text { Severe Abuse } \\
\text { OR SE) }\end{array}$ & $\begin{array}{c}\text { Very Severe Abuse } \\
\text { OR (SE) }\end{array}$ & $\begin{array}{l}\text { Neglect } \\
\text { OR (SE) }\end{array}$ \\
\hline Male & $.141(.278)$ & $.495(.339)$ & $.697^{+}(.433)$ & $.143(.368)$ \\
\hline Parent Age $<20$ & $.772(.880)$ & $.915(.906)$ & $1.353(1.122)$ & $.813(1.00)$ \\
\hline Parent Age $21-40$ & $.086(.660)$ & $1.183 *(.622)$ & $.476(.871)$ & $.537(.774)$ \\
\hline Parent Age $>40$ & $.154(.651)$ & $1.387 * *(.609)$ & $.596(.850)$ & $.478(.748)$ \\
\hline Unemployed & $1.74(.699)$ & $.888(.389)$ & $1.01(.576)$ & $1.16(632)$ \\
\hline Single parent & $3.10 * * *(1.08)$ & $2.46^{+}(1.22)$ & $1.83^{+}(.668)$ & $1.45(.797)$ \\
\hline Instability & $.699(.184)$ & $1.21(.361)$ & $2.59 * *(.792)$ & $2.33 * *(.794)$ \\
\hline Low education & $.662(.222)$ & $2.87 * *(1.18)$ & $1.93(.961)$ & $1.58(.737)$ \\
\hline Low income & $1.05(.307)$ & $1.59(.545)$ & $3.47 * * *(1.13)$ & $1.11(.421)$ \\
\hline Alcohol Abuse & $1.90 *(.552)$ & $3.59 * *(1.56)$ & $1.81(.750)$ & $1.84^{+}(.634)$ \\
\hline Used Abuse & $1.50(.378)$ & $1.23(.402)$ & $1.87^{+}(.641)$ & $2.18 *(.897)$ \\
\hline Family crowd & $-.621 *(.200)$ & $.886(.320)$ & $.540(.301)$ & $1.06(.509)$ \\
\hline
\end{tabular}


The first question when looking into the personal characteristics is whether abusers are more likely to be male or female. It can be seen from table 2 , men do not show clearly association. It shows that men have weak association with just very severe abuse. Statistically, men have 0.697 higher to use rude actions such as grabbed him/her around the neck and choked him/her or burned and scalded him/her on purpose. This result is supported through other research. Jenny C et al (2009) said that men are the most common perpetrators of life-threatening head injuries, abusive fractures and other fatal injuries.

As mentioned, young parents have a higher risk to do physical abuse. However, being young parents in Vietnam has no relationship with all types of physical abuse. It could be because Vietnamese culture dictates that when young couples normally live with their parents and receive support from grandmothers or grandparents. Thus may be a great resource to prevent child abuse.

Studies from Bangladesh, Colombia, Italy, Kenya, Sweden, Thailand and the United Kingdom have found that low education and a lack of income to meet the family's needs increase the potential of physical violence towards children (Bardi M Borgognini-Tari SM, 2001; Hadi A, 2000; Isaranurug S et al, 2001; Klevens J, Bayo'n MC, Sierra M, 2000; Lindell C, Svedin CG, 2001). The same results are also found here. Results show that low education and low income have strong relationships with child severe and very severe physical abuse. Vietnamese couple with low levels of education have 2.87 times higher odds to perpetrate severe abuse of their children.

Low income has the strongest relationship with very severe physical abuse. Statistically, people having low incomes have 3.47 times higher odds to do very severe abuse against their child than people with better incomes. This may be because low income is adversely associated with higher parental stress and depression, which in turn may result in harsh or neglectful parenting (Conger et al., 2002; VotrubaDrzal, 2003).

Findings from studies show more results about the relationship of child abuse and risk factors. Physically abusive parents are more likely to be young, single, poor and unemployed and to have less education than their non-abusing counterparts. In both developing and industrialized countries, poor, young, single mothers are among those at greatest risk for using violence towards their children (Straus MA et al 1998). Here, being a single parent in Vietnam also has a relationship with severe physical abuse. Richard (2010) explains that single parent spend more time to work for sustaining the household economy. They get more stress and do more physical abuse of their children.

Table 2 shows that alcohol abuse has relationships with almost all child maltreatment in Vietnam. An alcohol abusing parent has 1.90 times higher odds to do minor physical abuse and 3.59 times higher odds than non alcohol abusing parents of using severe physical abuse on their children. This result is similar with findings from the study by the Vietnam Social Issues Committee. It found that the direct cause (60 percent) of domestic violence and child abuse is alcohol abuse (Dung. N,T, 2007). It is an alarming number because the rate of alcohol abuse in Vietnam is quite high, from 7 to 11 percent in urban areas (Medical Ministry's study, 2011).

Family overcrowding and instability are two risk factors that have relationships with physical abuse. However, contrary with instability which increases odds of physical abuse, many people in family may reduce risk of minor physical abuse. From table 10, we can see that a family with many people statistically has 0.621 times lower odds of minor physical abuse. It may provide indirect support of the statement above that parents living with grandmothers and grandfathers have higher chances of reducing physical abuse.

For child neglect, this study shows that almost all risk factors had no relationship with child neglect. It is quite contrary to findings from other studies which state that domestic violence (Shepard \& Raschick 1999; Cawson 2002), unemployment (Creighton 1992 cited in Minty \& Pattinson 2004), and poverty (Thoburn et al 2000) are factors which increase the likelihood of neglect. In this study, only the variable of used abuse and instability have relationships with child neglect. Dubowitz $\mathrm{H}$, Black MB (2001) stated that unstable family environments, such as family members and others moving in and out, are a feature particularly noted in cases of child neglect. This appears to be true in Vietnam, families 
which always have to move or change their place will have less time to care for their children because they have to pay more time to do other things such as looking for jobs. Logically, they will not have time to care for their children thus child neglect becomes more likely.

Children who are maltreated are more likely to go on to become maltreating parents themselves, thus perpetuating the cycle of abuse and neglect and exposing another generation of children to maltreatment (e.g. WHO, 2006). This may be true because in this study, parents who were abused not only had a relationship with child neglect but also with very severe physical abuse. In Vietnam, studies indicate that people who experienced violence or abuse have more behaviour problems, such as aggressive behaviour than others (Mai, B,T,. 2009). Studies have not explained why this happens. However, social learning theory suggests that child abuse is learned behavior. Violence in families is seen as a predictive factor for violence in future (Newberger, M.D \& Robert., LH, 2003). It is consistent with other theories when found that individuals who have experienced violent and abusive childhoods are more likely to grow up to become child and spouse abusers than individuals who experienced little or no violence in their childhood years (Parke and Collmer, 2005). Being maltreated, if it causes any consequences to children? Table below present the situation about child behavior problems.

Table 3: Distribution of Child behaviour problems

\begin{tabular}{lc}
\hline Child behaviour problem & Percent \\
\hline Anxious & 46.1 \\
Withdraw & 19.5 \\
Somatic problem & 12.3 \\
Rule Breaking & 33.8 \\
Aggressive & 31.4 \\
\hline
\end{tabular}

From table 3, it seems child maltreatment causes many problems for children. Table 3 shows that 46.1 percent of children having symptoms of anxiety. It is the biggest problem which abused children are faced with. Actually, children are a vulnerable group and they are likely to be hurt by adults. Thus, they often fear many things in the environment. Approached with children who are abused, at the beginning, normally they shiver and cry if someone touch them. (Mai, B,T,. 2009).

Rule Breaking and Aggressive behaviour are also problems which many children are developing. And here, we can see that there are 31.4\% having at least 1 symptom of aggressive behaviour in last 6 months. The rate of children getting in rule breaking behaviour is also high $(33.8 \%)$.

Withdraw and somatic problems seem to have lower rates than other problems above. Withdraw problems are at 19.5\%; and Major withdrawal problems are just $12.3 \%$. Table 3 just shows basic numbers about children's problems.

Researchers have found that child abuse and neglect have relationships with behavior problems in childhood and adolescence (Ethier et al., 2004; Mills, 2004; Shaffer, Huston, \& Egeland, 2008). The earlier children are maltreated the more likely they are to develop behavior problems in adolescence (Frederico et al., 2008). Researchers have often associated abuse and neglect with internalizing behaviors (being withdrawn, sad, isolated and depressed) and externalizing behaviors (being aggressive) throughout childhood (Mills, 2004). Studies also show that mental health problems, such as depression and anxiety disorders, have consistently been linked with child abuse and neglect, particularly for adolescents (Gilbert et al., 2009; Harkness \& Lumley, 2008). So, it seems children, including Vietnamese children, develop many problems if they are maltreated. 
Table 4: Random effects regression models: Child maltreatment and child problems

\begin{tabular}{|c|c|c|c|c|c|}
\hline Variable & $\begin{array}{l}\text { Anxious } \\
\text { B (SE) }\end{array}$ & $\begin{array}{c}\text { Withdraw } \\
\text { B (SE) }\end{array}$ & $\begin{array}{l}\text { Somatic } \\
\text { B (SE) }\end{array}$ & $\begin{array}{c}\text { Breaking rule } \\
\text { B (SE) }\end{array}$ & $\begin{array}{c}\text { Aggressive } \\
\text { B (SE) }\end{array}$ \\
\hline Minor abuse & $-.014(.309)$ & $-.735(.348)$ & $-.018(.481)$ & $.386(.319)$ & $-.604(.349)$ \\
\hline Severe abuse & $1.021 * *(.380)$ & $.942 *(.434)$ & $1.412 * *(.508)$ & $.314(.369)$ & $1.050 * *(.395)$ \\
\hline $\begin{array}{l}\text { Very severe } \\
\text { abuse }\end{array}$ & $.629(.557)$ & $2.390 * * *(.644)$ & $.433(.617)$ & $-.145(.544)$ & $-.096(.590)$ \\
\hline Neglect & $-.083(.476)$ & $-.2166(.563)$ & $1.171 *(.569)$ & $1.136(.461)$ & $1.283 *(.498)$ \\
\hline Number Crowed & $-.645 *(.322)$ & $.023(.405)$ & $-.627(.536)$ & $-.788 *(.340)$ & $-.829 *(.371)$ \\
\hline Used Abuse & $-.028(.310)$ & $.624(.404)$ & $.541(.428)$ & $.012(.307)$ & $-.258(.350)$ \\
\hline Alcohol abuse & $.481(.330)$ & $.198(.445)$ & $-.307(.487)$ & $.060(.325)$ & $.491(.364)$ \\
\hline Low income & $.0101(.306)$ & $-.245(.414)$ & $.716(.446)$ & $-.290(.314)$ & $.041(344)$ \\
\hline Low education & $-.085(.332)$ & $.550(.403)$ & $-1.02^{+}(.561)$ & $-.429(.341)$ & $-.176(.361)$ \\
\hline Unemployment & $.302(.411)$ & $-1.943 *(.895)$ & $.043(.595)$ & $.192(.404)$ & $.215(.470)$ \\
\hline Instability & $-.110(.243)$ & $.1361(.363)$ & $-.322(.431)$ & $.167(.274)$ & $.222(.303)$ \\
\hline Single parent & $.461(.502)$ & $-.265(.656)$ & $-.069(.721)$ & $-.564(.542)$ & $-1.191 *(.760)$ \\
\hline Child Male & $-.055(.226)$ & $.684^{+}(.373)$ & $-1.356 * *(.442)$ & $.524^{+}(.278)$ & $-.312(.303)$ \\
\hline Male & $-.016(.2741)$ & $-.025(.369)$ & $.266(.416)$ & $.128(.277)$ & $-.140(.309)$ \\
\hline
\end{tabular}

Using regression models with cluster corrections, I test relationships between child behavior problems and child maltreatment. As can be seen from table 4 not all types of child maltreatment have relationships with child behavior problems. Table 4 shows that child minor abuse has no relationship with types of child behaviors. Actually, as discussed above, actions such as hit on the bottom with something like a rod, hairbrush, a stick, or slap on the hand, arm, or leg culturally are accepted by both parents and children. So, children feel also normal if they have suffered minor physical abuse.

Minor abuse does not result in many problems in children's behavior however on the other hand children get many problems when they experience severe physical abuse from their parents. As can be seen from table 4 , severe physical abuse has a relationship with almost all problems except rule breaking. Statistically, we believe that children have around more than 1 times higher odds of being anxious, having somatic problems, withdrawal behavior and aggressive attitudes with others if parents use actions such as knocking down, beating or kicking their children.

In this study, very severe abuse does not have a relationship with many child problems, just withdrawal behaviors. However, we can see that that is a very strong relationship and very severe. Statistically, children have around 2.3 times higher odds of getting withdraw behavior if they are severely abused physically. It is really dangerous for child development when they become adults. This indicates an urgent need to have interventions immediately.

Aggressive behaviors and somatic problem are commonly associated with child neglect. Children affected by neglect tend to be more isolated at school compared to other groups of children and have difficulty making friends (Hildyard \& Wolf, 2002). Sometime, because of being neglected, those children may also display aggressive and disruptive behavior (Hildyard \& Wolf, 2002; Holt, Buckley, \& Whelan, 2008). Thus, it also causes some somatic problems. As discussed above, recently, the prevalence of school bullying in Vietnam has been increasing rapidly (Tham. LTH, Kien. TG, 2009). Case studies show that many bullies live in families with less caring from their parents (Tham. LTH, Kien. TG, 2009). Thus, without caring and orientation from parents or caregivers, children may be at 
high risk to get involved in deviant behaviors such as aggression for male children or withdrawal for female children.

In general, we can see that being abused by their parents, children are at risk for many problems including internalizing and externalizing problems. Discussing about withdrawal behavior of children related to abuse, Thiem (2010) pointed out that when they are abused, normally children show two reactions. First are externalizing problems such as changing attitudes quickly, easily angered, aggressiveness, crying a lot and so on. The second reaction is that children often show behaviors such as withdrawing and worry. They often feel sad, do not want to contact others and isolate themselves from others. Also, more children develop the second type of reaction than the first (Thiem, 2010). Being directly abused by their parents, normally children will lose confidence in their parent. Actually, at the beginning of life, their parents are persons to whom they attach, receiving love and care from them. However, if parents use rude actions (physical abuse) toward their children, children may be really hurt and it is understandable when they withdraw and do not want to play with others. In reality, children have good development, in terms of physical and mental health, if they have good interactions with others. But abused children often speak less, isolate themselves from others so it is dangerous for the development of such children.

Physical abuse also has great negative influence on child development. Severe abuse such as beating, fighting, kicking hard to the child's head or any part of the child results in severe consequences to children. Reports from the General hospital in Vietnam (2011) shows that children having symptoms of severe physical abuse also have symptoms of body breakdown, headaches or nightmare. Definitely, if such symptoms happen frequently, then child development is endangered.

Children suffering from maltreatment have more aggressive behavior and rule breaking at home. For those children, they feel despair and feel fed up with their family so they do everything they want, even behavior such as aggression or breaking rules. Some of them MAY do that just to receive attention from their parents. Recently in Hanoi and Vietnam, rates of drop out and school bullying have been increasing rapidly. Interviews from those children indicate many of them answer that nobody cares for them and also they simply do not want to go to school. Some of them said, they always come to school in a sad mood so it is easy to fight with others (Case study, 2011). Many children also break the family rules because they could not endure physical violence or nobody cares for them (neglect). Because the family is not a safe environment anymore many of them break the family rules and run away from home. Being children, it is really dangerous for them if they have to live far from their families. Consequences can be seen through reports from policemen in 2009. The report shows that rates of teenage sex workers are higher in Hanoi and Hochiminh. Furthermore, recently, more adolescent have been involved in criminal cases such as fighting, drug abuse, illegal car racing, rape etc. This is an alarming situation and really needs intervention by society.

According to the Ministry of Labor, Invalids and Social Affairs (2009), many reasons cause child maltreatment such as an undisciplined legal system, lack of awareness and lack of knowledge in caring for children, weak collaboration among family members, schools and society in caring for children etc. Recently, the Vietnamese Care Children Strategy from 2011 to 2015 pointed out that effective intervention for children should be based on community and neighborhoods. Based on that, the Child Protection Department under the Ministry of Labor Invalid and Social Affairs has prepared a Project to move children in social protection centers to communities.

\section{Conclusion}

The purpose of this study is to examine the situation of child maltreatment in Vietnam and the findings show that rate of child maltreatment in Vietnam is prevalent and high. Discussing risk factors, findings in this study are consistent with other research and studies. It shows that child maltreatment has relationships with many risk factors such as poverty, unemployment, instability, alcohol abuse etc. Therefore, interventions to prevent child maltreatment should pay more attention to those risk factors. However, one thing which is not clearly mentioned in previous studies in Vietnam is about parent used 
abuse. But it shows clearly in this study that perpetrators have close relationship with used abuse. Then it could be seen here that child maltreatment may not only cause short term negative consequences to child development but may also cause long term effects on later generations. Thus, on a more positive note: the benefits of preventing maltreatment are also potentially intergenerational - programs that reduce maltreatment in the current generation of children should provide additional pay-offs in the form of reduced maltreatment in the next generation.

Studies show that there is a high rate of child maltreatment when children are young. However, the rate goes down when children grow up. But findings in this study seem different. It could be seen that the highest rate of child maltreatment is found among children aged over 15 years old. Reasons have been discussed and we learnt that pressure of education could be a great risk factor for parent-child conflict including child maltreatment (Human development institute, 2010). In Vietnam, children have been pressured more and more from education. Recently, many people argued about heavy study programs for children. Parents also have high expectations of their children in study. They invest much energy to push up their children to study, especially for older children to enter university, which may cause pressure and resistance from children.

In Vietnam, recently, rates of teenage and adolescent crime and deviant behavior have increased (Children Protection and Care Department, 2008). There are many reasons that have been brought out to explain it but arguments still remain. This is because there is no competent research exploring the relationship between child behavior problems and other causes. In this study, the findings are firm and worthy of confidence. In this study, findings show that child maltreatment has a relationship with many types of behavior problems. In other words, suffering from maltreatment, children are more likely to develop both internalizing and externalizing problems.

\section{References}

Adinkrah, M. (2000). Infanticides in Fiji. Child Abuse \& Neglect, 24:1543-1555.

Bardi, M. (2001). A survey of parent-child conflict resolution: intrafamily violence in Italy. Child Abuse \& Neglect, 25:839-853.

Browning, C. (2002). The Span of Collective Efficacy: Extending Social Disorganization Theory to Partner Violence. Ohio State University. Published by: National Council on Family Relations.

Coulton, C. J., Coulton, J. E., Korbin, M., \& Chow, J. (1995). Community level factors and child maltreatment rates. Child Development, 66 (1995), pp. 1262-1276. Full Text via CrossRef $\mid$ View Record in Scopus | Cited By in Scopus (213).

De, B. M., \& Thomas, L. (2003). Biologic findings of post-traumatic stress disorder and child maltreatment. Current Psychiatry Repots, 5, 108-117.

Dubowitz, H., Black, M. B. (2001). Child neglect. In: Reece RM, Ludwig S, eds. Child abuse: medical diagnosis and management. 2nd ed. Philadelphia, PA, Lippincott Williams., \& Wilkins, 2001:339-362.

Dubowitz, H., Papas, M. A., Black, M. M., \& Starr, R. H. (2002). Child neglect: Outcomes in highrisk urban preschoolers. Pediatrics, 109, 1100-1107.

Durrant, J. E. (2005). Corporal Punishment: Prevalence, Predictors and Implications for Child Behaviour and Development. In: Hart SN (Ed) (2005). Eliminating Corporal Punishment Paris, UNESCO.

East-Asia. (2009). People's Republic of China Hong Kong, China Republic of Korea, Mongolia, Taipei, China.

Emery, C., Jolley, L., \& Wu. (2010). Intimate partner violence relationship dissolution among couples with children: the counterintuitive role of "Law and Order" neighborhoods. Journal of Community Psychology. vol. 38, no. 4, 2010.

English, D. J., Widom, C. S., \& Brandford, C. (2004). Another look at the effects of child abuse. NIJ journal, 251, 23-24.

Habasch, R. (2005). Physical and Humiliating Punishment of Children in Yemen. Save the Children Sweden. Cited in: International Save the Children Alliance (2005). Ending Physical and 
Humiliating Punishment of Children.Making It Happen, Part 2. Global Submission to the UN Secretary-General's Study on Violence against Children. Stockholm, Save the Children Sweden. Jenny, C. (2009). Analysis of missed cases of abusive head trauma. Journal of the American Medical Association, 281:621-626.

Kim, D. (2008). Blues from the neighborhood? Neighborhood characteristics and depression. Epidemiol Rev. 2008; 30(1):101-117.

Kirschner, R. H. Wilson, H. (2001). Pathology of fatal child abuse. In: Reece RM, Ludwig S, eds. Child abuse: medical diagnosis and management, 2nd ed. Philadelphia, PA, Lippincott Williams., \& Wilkins, 2001:467-516.

Menick, D. M. (2000). Les contours psychosociaux de l'infanticide en Afrique noire: le cas du Se'ne'gal. [The psychosocial features of infanticide in black Africa: the case of Senegal.] Child Abuse \& Neglect, 2000, 24:1557-1565.

Nguyen, T. N. (2009). Child maltreatment and the view of "Whip love". Hochiminh's Research Institute.

Sampson, R. J., Stephen, W. R., \& Felton, E. (1997). Neighborhoods and violent crime: A multilevel study of collective efficacy. Science 277:918-924.

Springer, K. W., Sheridan, J., Kuo, D., \& Carnes, M. (2007). Long-term physical and mental health consequences of childhood physical abuse: Results from a large population-based sample of men and women. Child Abuse \& Neglect, 31, 517-530.

UNICEF (2009). Child Protection from Violence, Exploitation and Abuse http://www.unicef.org/media/media_45451.html.

UNICEF (2010). Report Child Abuse \& Neglect. 2010. 